\title{
Multidetector computed tomography findings of an asymptomatic levoatrial cardinal vein with an interatrial course
}

\author{
B. Genç ${ }^{1}$, A. Solak ${ }^{1}$, N. Şahin ${ }^{1}$, S. Gür ${ }^{1}$, A. Öztürk² , S. Kalaycıoğlu ${ }^{1}$ \\ ${ }^{1}$ Department of Radiology, Sifa University, Izmir, Turkey \\ ${ }^{2}$ Department of Cardiology, Sifa University, Izmir, Turkey
}

[Received 26 January 2013; Accepted 11 March 2013]

\begin{abstract}
A 57-year-old female patient with a family history of coronary artery disease admitted to our hospital for the coronary check-up. A coronary angiography was performed with ECG-gated 128 slice dual source computed tomography. Multidetector computed tomography (MDCT) showed, in addition to the normal coronary arteries, a persistent levoatrial cardinal vein (LCV) draining into vena cava superior. ECG-gated cardiac MDCT is a useful tool showing the origin, course, and drainage site of LCV. (Folia Morphol 2013; 72, 3: 274-277)
\end{abstract}

Key words: multidetector computed tomography, levoatrial cardinal vein

\section{INTRODUCTION}

Levoatrial cardinal vein (LCV) is a very rare congenital anomaly that is an embryologic remnant of venous system. It was first described by Macintosh in 1926 as an abnormal vein establishing a link between left atrium or pulmonary vein and systemic vein [10]. Edwards and DuShane [3] described this venous structure as an abnormal vein in a case with mitral atresia. This vein allows that pulmonary blood flows to systemic veins at embryologic period. It generally originates from left atrium or more commonly from pulmonary veins and drains into superior vena cava (SVC) or innominate vein [6]. It is usually observed with obstructive lesions at the outflow of left atrium. As LCV is an embryologic remnant of venous system, it is usually not observed in adulthood. A few cases diagnosed postnatally have been defined in the literature. To our knowledge, this is the first case with the asymptomatic LCV diagnosed with multidetector computed tomography (MDCT).

\section{CASE REPORT}

A 57-year-old female patient admitted to our department of radiology for the purpose of making the coronary check-up with coronary calcium scoring and coronary computed tomography angiography examination. She had no disease history, but her family history was remarkable for coronary artery disease. On the physical examination her blood pressure was 110/75 mm Hg, pulse rate was 75 bpm, and respiratory rate was 15 breathes per minute. Her ECG was normal sinus rhythm.

ECG-gated MDCT (Somatom Definition, 128-slice Dual Source CT, Siemens Medical Systems, Erlangen, Germany) was carried out. Contrast material of $80 \mathrm{~mm}^{3}$ (Ultravist $370 \mathrm{mg} / \mathrm{mL}$, Schering, Germany) was given through the antecubital vein at a rate of $6 \mathrm{~mm} / \mathrm{s}$.

Afterwards, 50-cc of intravenous saline solution was given as a bolus at a rate of $5 \mathrm{cc} / \mathrm{s}$. The ascending aorta was used as a reference point for location of the region of interest $1 \mathrm{~cm}$ distal to the tracheal bifurcation. Two seconds after the threshold level reached 150 Hounsfield units (HU), the scan was automatically started. Bolus tracking was employed for the control of contrast administration. The following protocol was used as a guidance for ECG-gated MDCT: detector collimation, $32 \times 0.6 \mathrm{~mm}$; gantry rotation time, $330 \mathrm{~ms}$ (temporal resolution, $83 \mathrm{~ms}$ ); slice acquisition, 

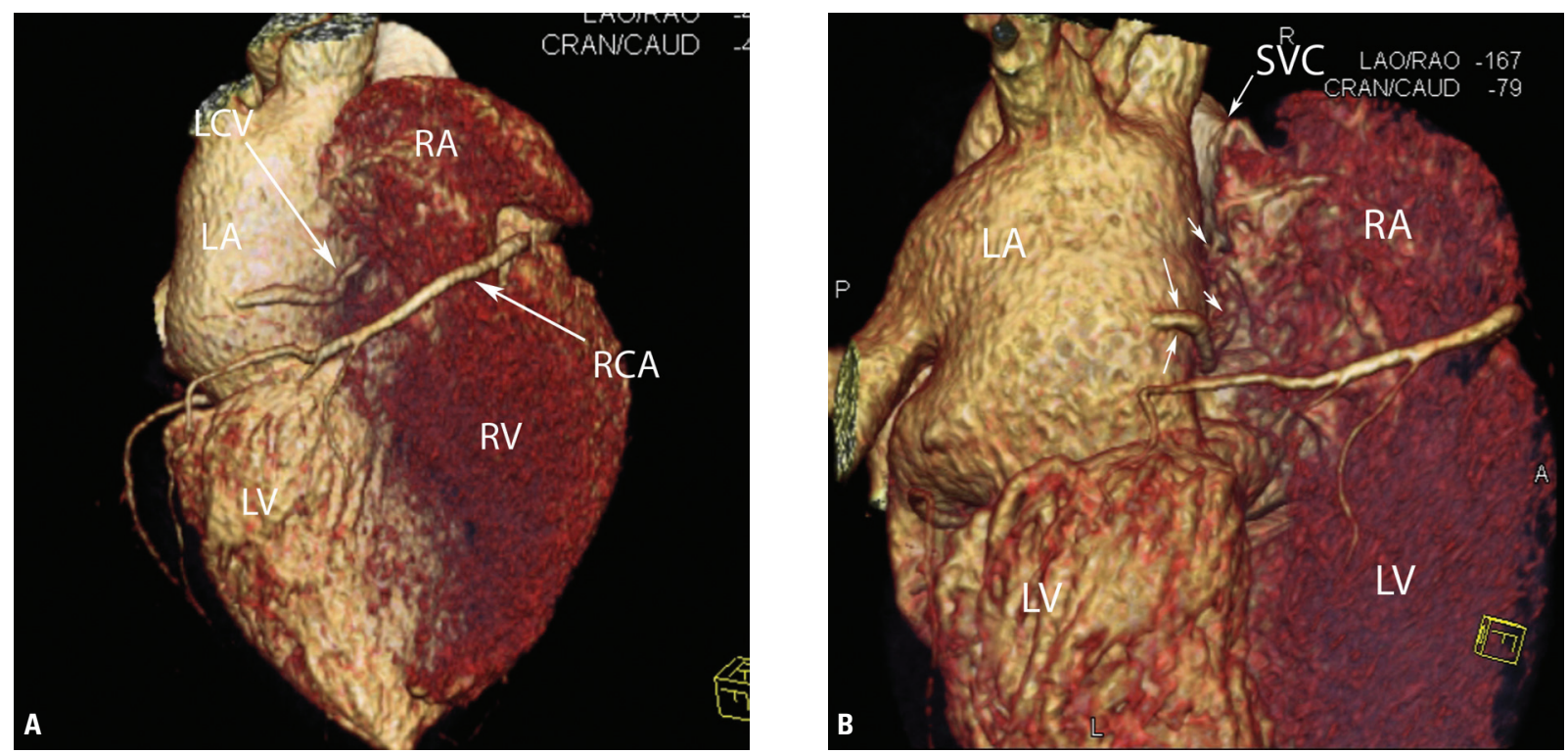

Figure 1. Posterior view 3-dimmensional volume rendered images (A, B) of the heart show levoatrial cardinal vein (LCV, white arrows) with an interatrial course, originating from the inferomedial part of left atrium (LA) and draining into superior vena cava (SVC).

$64 \times 0.6 \mathrm{~mm}$; pitch, 0.26 adapted to the heart rate; tube voltage, $120 \mathrm{kV}$; tube current, $420 \mathrm{mAs}$ per rotation.

MDCT showed a venous structure with a diameter of $4 \mathrm{~mm}$ and a length of $7 \mathrm{~cm}$ that originates from the inferomedial part of the left atrium, courses interatrially, and drains proximally into the SVC (Figs. 1, 2). That venous structure was consistent with LCV that was an embryologic remnant. Interatrial septum and interventricular septum were intact. A total of 4 pulmonary veins were detected, 2 being on the left and 2 on the right side. No additional cardiac pathology was detected. As the patient was asymptomatic, no therapy was given. She attended follow-up at the cardiology clinic.

\section{DISCUSSION}

LCV is an embryonic remnant of the venous system. Cardinal veins provide the main venous drainage of the embryonic body. At the early period of development bilateral cardinal venous systems exist. At this stage of development cardinal veins establish the connection between the heart and the pulmonary vascularity. Subsequently, vena cava system develops as the anastomoses between cardinal veins become established and pulmonary veins are connected to left atrium [11]. Levoatrial cardinal vein may be persistent in cases where foramen ovale prematurely closes or there is a severe left-sided obstruction such as mitral atresia or aortic atresia. As this vein interconnects caval venous system and pulmonary venous drainage, there is no or limited other exit for the blood in the atrium. LCV generally originates from left atrium and more commonly from pulmonary vein and drains into SVC or innominate vein [6].

Since this pathology is far less common than other cardiovascular pathologies, its prenatal and postnatal diagnosis is quite challenging. A LCV draining into innominate vein was diagnosed at prenatal period for the first time in a 23-week fetus with double outlet right ventricle and mitral atresia [12].

Despite the fact that it is known that LCV is associated with mitral atresia, aortic atresia, or aortic stenosis, it has been reported to be associated with cor triatriatum [4, 12]. Fujiwara et al. [5] reported a case of tetralogy of Fallot without left ventricular hypoplasia, which had a levoatrial cardinal vein. That case was surgically treated. Alcibar et al. [1] treated LCV with percutaneous transcatheter embolisation method.

Kaneda et al. [7] reported an adult case with no congenital or acquired heart disease other than LCV. However, that case was repaired by the open surgery due to being symptomatic and due to increased shunt fraction 3 years after the diagnosis. In that case LCV originated from the roof of left atrium and joined SVC. That case was originally described as a case of partial venous return anomaly without atrial septal defect that could not be fully delineated with echocardiography and conventional angiography. Final diagnosis and exact characterisation of the abnormal artery was only possible with 3-D MDCT. 

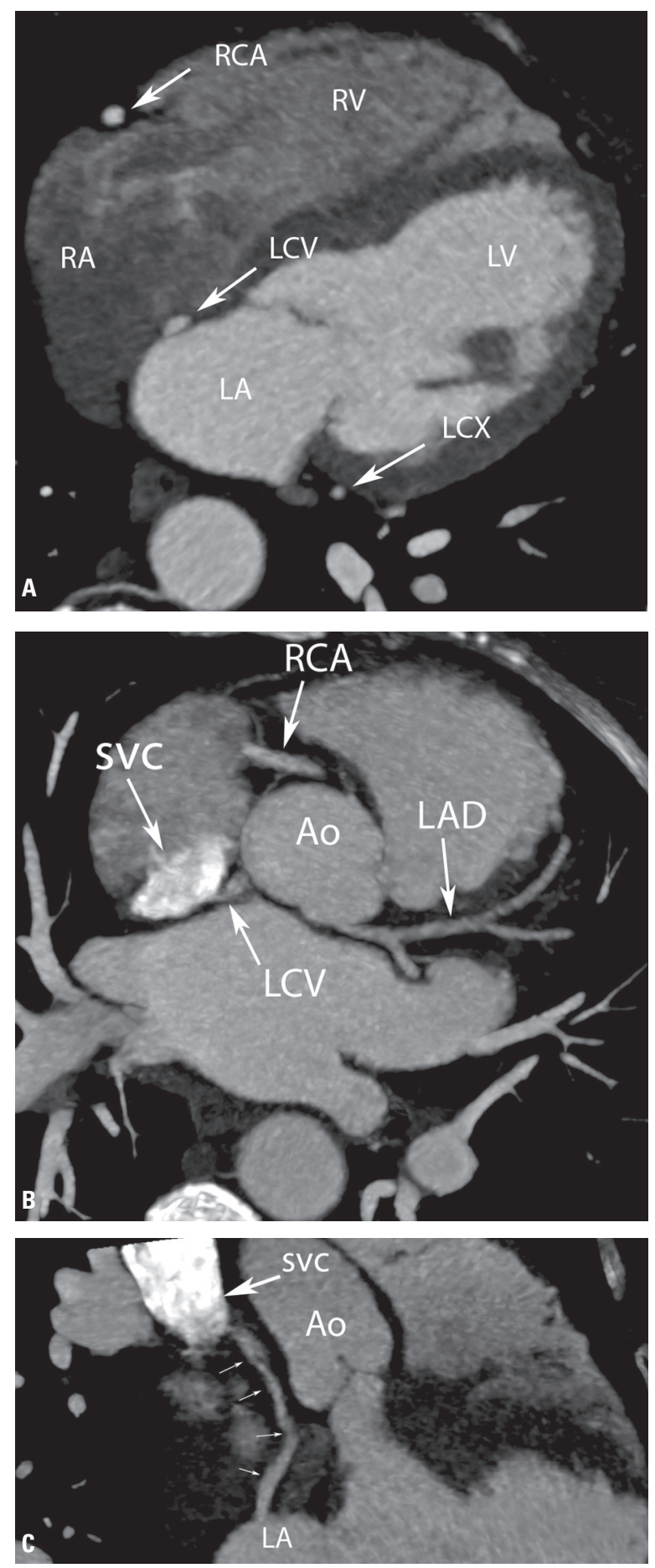

Figure 2. Axial MIP images (A) show levoatrial cardinal vein (LCV) with an interatrial course. Interatrial and interventricular septa are intact; B. LCV is observed that drains into superior vena cava (SVC). Coronal MIP image (C) shows LCV (white arrows) that originates from the atrium and courses in a cranial direction; RA — right atrium; LA — left atrium; RV — right ventricle; LV — left ventricle; RCA — right coronary artery; LCX — left circumflex artery; Ao aorta; LAD — left anterior descending artery.
Our case is the only asymptomatic adult case in the literature, which was diagnosed with MDCT and had no additional cardiac pathology. Treatment is necessary is cases with LCV that is symptomatic. Transcatheter embolisation is the treatment of choice in suitable cases. The treatment method in cases not suitable for that method is surgical ligation and treatment of cardiac pathologies. Follow-up suffices in the asymptomatic cases.

Other techniques used in the diagnosis of LCV are echocardiography and selective angiography. Echocardiography is usually the first imaging technique in cardiovascular pathologies. However, neither transthoracic nor transoesophageal echocardiography can easily define these veins as they are extracardiac. Hence, cases diagnosed as having LCV were not diagnosed by echocardiography $[1,7]$. Other technique for diagnosis is selective cardiac angiography, however, this method is costly and invasive. Even with this technique the origin of the abnormal vein may not be localised accurately [1]. Experts recommend using MDCT for diagnosis because of challenges experienced in detection of this vein [4, 7].

ECG-gated CT is the noninvasive method commonly used at recent period for assessment of other cardiac structures in addition to coronary arterial and venous anomalies [2, 8, 9]. The high temporal resolution, multiplanar reconstruction (MPR) and 3D volume rendering technique (VRT) and maximum intensity projection (MIP) features provided by this technique enables a detailed evaluation of vascular anomalies and pathological cardiac structures.

In our case MDCT showed an asymptomatic LCV that was the embryologic remnant between left atrium and SVC.

\section{CONCLUSIONS}

In conclusion, ECG-gated cardiac MDCT is a useful method that shows vascular structures such as LCV, their origin, course, and drainage site.

\section{REFERENCES}

1. Alcibar J, Gómez $S$, Vitoria $Y$, Jiménez $A$, Peńa N, Ońate $A$, Cabrera A, Martínez P (1999) Occlusion of the levoatrial cardinal vein with Giantico coils after Fontan operation. Rev Esp Cardiol, 9: 733-736.

2. Bayraktutan $U$, Kantarci $M$, Olgun $H$, Kizrak $Y$, Pirimoglu $B$ (2012) Partial anomalous pulmonary venous return associa- 
ted with vascular anomalies of the aorta: multidetector computed tomography findings. Folia Morphol, 71: 115-117.

3. Edwards JE, DuShane JW (1950) Thoracic venous anomalies. Mayo Clin Proceed, 50: 599-600.

4. Feltri C, Crawley C, Peart I, Pozzi M, Corno AF (2008) Late presentation of cor triatriatum with persistent levoatrial cardinal vein. Asian Cardiovasc Thorac Ann, 16: 149-151.

5. Fujiwara $K$, Naito $Y$, Komai $H$, Noguchi $Y$, Nishimura $Y$, Uemura S, Hirayama K, Suzuki H (1999) Tetralogy of Fallot with levoatrial cardinal vein. Pediatr Cardiol, 20: 136-138.

6. Gaynor JW, Weinberg PM, Spray TL (2000) Congenital Heart Surgery Nomenclature and Database Project: systemic venous anomalies. Ann Thorac Surg, 69: S70-S76.

7. Kaneda T, Onoe M, Matsuda M, Moriwaki S, Mori N (2006) Patent levoatrial cardinal vein without left heart hypoplasia. Ann Thorac Surg, 81: 740-742.
8. Kantarci M, Doganay S, Karcaaltıncaba M, Karabulut N, Erol MK, Yalcin A, Duran C, Dursun M, Karakaya A, Tatli S (2012) Clinical situations in which coronary CT angiography confers superior diagnostic information compared with coronary angiography. Diagn Interv Radiol, 18: 261-269.

9. Kantarci M, Yuce I, Yalcin A, Arslan S, Bozkurt M Gundogdu F (2011) Evaluating adult cor triatriatum with total anomalous pulmonary venous connections by multidetector computed tomography angiography. Folia Morphol, 70: 312-314.

10. Macintosh CA (1926) Cor biatrium triloculare. Am Heart J, 7: 735-744.

11. Sadler TW (1995) Langman's medical embryology. Williams and Wilkins, Baltimore, MD 1995; 219-224.

12. Tutschek B, Schmidt KG (2008) Levoatrial cardinal vein in mitral atresia and closed foramen ovale: prenatal diagnosis and perinatal management. Ultrasound Obstet Gynecol, 32: 229-232. 